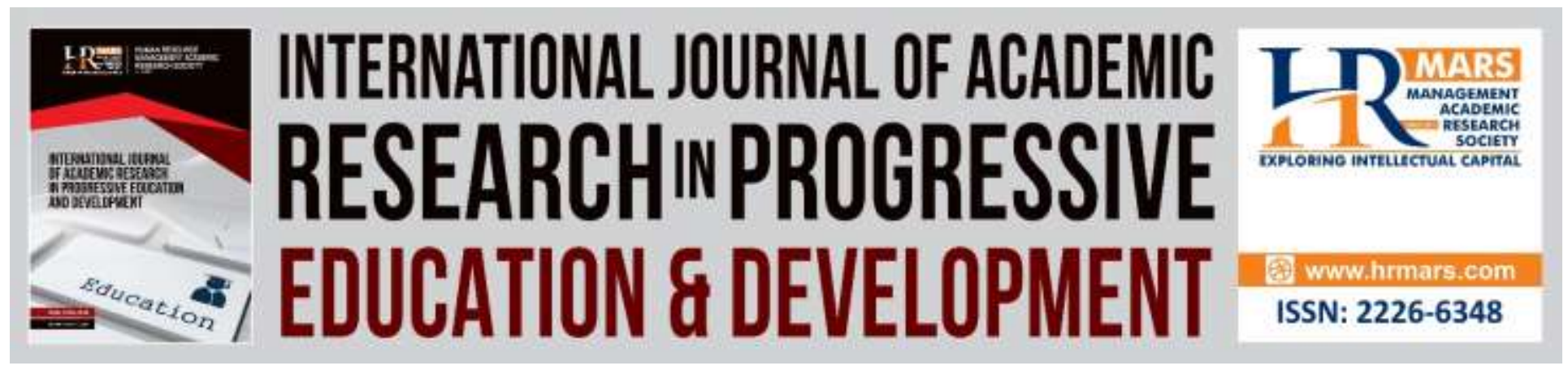

\title{
The Effectiveness of Using I-Think Thinking Map in Enhancing the Mastery of Malay Language Essay Writing Skills of Form 6 in Mukah District
}

\section{Zamri Mahamod, Anthony Aloysius Akup \& Hadi Hassan}

To Link this Article: http://dx.doi.org/10.6007/IJARPED/v8-i4/6543

DOI:10.6007/IJARPED/v8-i4/6543

Received: 15 October 2019, Revised: 05 September 2019, Accepted: 25 September 2019

Published Online: 04 November 2019

In-Text Citation: (Mahamod, Akup, \& Hassan, 2019)

To Cite this Article: Mahamod, Z., Akup, A. A., \& Hassan, H. (2019). The Effectiveness of Using I-Think Thinking Map in Enhancing The Mastery of Malay Language Essay Writing Skills of Form 6 in Mukah District.

International Journal of Academic Research in Progressive Education and Development, 8(4), 386-401.

\section{Copyright: (c) 2019 The Author(s)}

Published by Human Resource Management Academic Research Society (www.hrmars.com)

This article is published under the Creative Commons Attribution (CC BY 4.0) license. Anyone may reproduce, distribute, translate and create derivative works of this article (for both commercial and non-commercial purposes), subject to full attribution to the original publication and authors. The full terms of this license may be seen at: http://creativecommons.org/licences/by/4.0/legalcode

\section{Vol. 8(4) 2019, Pg. 386 - 401}




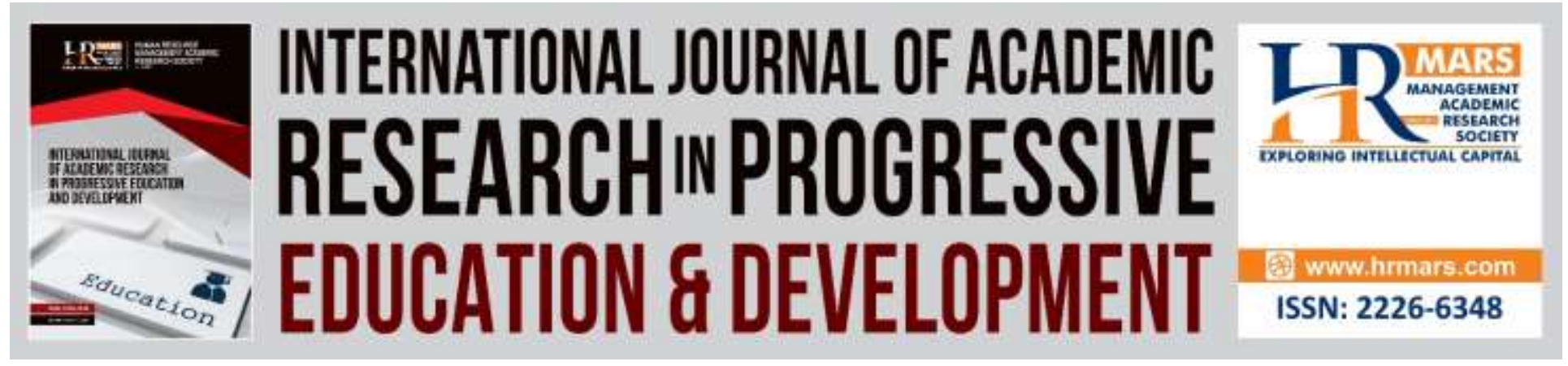

\title{
The Effectiveness of Using I-Think Thinking Map in Enhancing the Mastery of Malay Language Essay Writing Skills of Form 6 in Mukah District
}

\author{
Zamri Mahamod, Anthony Aloysius Akup \& Hadi Hassan \\ Faculty of Education, Universiti Kebangsaan Malaysia, 43600 UKM, Bangi, Selangor Darul Ehsan, \\ Malaysia
}

\begin{abstract}
I-Think thinking map is one of the teaching aids used to improve the thinking culture among students. The use of $\mathrm{i}$-Think thinking map in the teaching and Malay language essay teaching is essential to produce creative and critical thinking students. Therefore, the study aims to examine the effectiveness of using i-Think thinking map in the mastery of non-formatted Malay essay writing skills among form 6 students. A quantitative approach is used in this study by using a quasi-experimental design conducted over five treatments on form 6 students at one of the secondary schools in Mukah Division, Sarawak. Distribution of experimental group and control group is done according to the existing class. The experimental group consists of 20 students and same with the control group. Data were obtained from pre-test and post-test. The data were analyzed using independent and dependent $t$ test. The findings show that there is no significant difference in the writing of non-formatted essay for pre-test of the experimental and control groups. After treatment, there was a significant difference in the level of student achievement in essay writing for the post-test of the experimental group and control groups. Significant differences also exist for students' achievement in non-formatted essay writing in terms of relevance between pre-test and post-test for experimental group. There is also a significant difference in the development aspect of the experimental group between pre-test and post-test. Post-test mean score is higher than pre-test for both aspects. Significant differences also exist between experimental groups and control groups for relevance and development aspects in post-test. Experimental group mean score is higher than control group. This proves that the use of i-Think thinking map can improve students' achievement in the non-formatted essay writing among form 6 students.
\end{abstract}

Keywords: I-Thing Thinking Map, Malay Language Education, Essay Teaching.

\section{Introduction}

In today's globalized era full of challenges, the country needs human capital that has critical and analytical thinking as well as able to develop the nation towards more glorious direction. In line 
with this, Malaysia needs to produce students who are mature-minded, knowledgeable, and capable to communicate ideas effectively using various forms of communication (Malaysian Examinations Council, 2011). Hence, more emphasized should be given to the educational system which gives students the opportunity to generate ideas in the process of acquiring knowledge.

In this regard, the Malaysian Examinations Council (2011) introduced the new syllabus for the Malaysian High School Certificate (STPM) for Malay Language subjects to produce pre-university students who are able to speak Malay efficiently, to pursue higher education, be competitive and able to meet the needs of the job market as well as strengthen the love towards Malay language and proudly use it. One of the syllabus contents is the production of a non-formatted essay which requires students to give critical and analytical opinions and descriptions of a given topic. This requires a student who is able to produce brilliant and knowledgeable ideas on a subject.

As such, Malaysian Education Development Program has introduced i-Think Program to provide a new platform for teachers to attract students in the process of teaching and learning Malay language especially in essay writing. i-Think program also aims to improve and cultivate thinking skills amongst students in order to produce innovative students (Ministry of Education, 2015). This is especially emphasized by the ministry that the program is made compulsory in all schools in Malaysia. One of the tools used in i-Think program is i-Think thinking map. The use of i-Think thinking map is aimed at improving the practice and culture of high-level thinking among students. This i-Think thinking map is presented in 8 simple graphical formats that have their own unique thinking process. Therefore, the use of $i$-Think thinking map in the teaching and learning process is expected to train students to think deeper and more detailed on something as well as instill a high-level thinking culture within each student.

By using i-Think Thinking Map especially in essay teaching and learning, students are expected to achieve the objectives of STPM Malay Language syllabus (Malaysian Examinations Council 2011) that are more ready to write and develop the content of the essays in a more organized, compact and clear way to produce an intact discourse. Students are also expected to develop and process the ideas fluently and effectively and write essays that precisely address the topic in a fluent and effective language.

\section{Problem Statement}

In STPM Malay language syllabus, students are required to learn the non-formatted essays. Nonformatted essay writing was studied by the students in the first term of Form 6 school session. The main purpose of this non-formatted essay is to produce mature, creative and innovative preuniversity students.

However, based on the observations and exercises provided by the researcher throughout the teaching and learning process, most Form 6 students at one of the secondary schools in Mukah, Sarawak who took Malay language subject at the STPM level are still weak in writing the nonformatted essay. This is evident in the STPM Mid-Term Exam (school level); the student essay score is still at an unsatisfactory level. From the exam, no student gets marks between 35 and 50 . 
A total of 39.2 percent of students scored 30 to 34 marks, 53.5 percent of students scored 20 to 29 marks, and 14.28 percent of students scored at a weak level of less than 20 marks. This suggests that students are still problematic in producing good quality essays in content and development as well as conveying the content by using fluent and effective language.

Among the weaknesses that students did in essay writing are the problem of the content expressed by the students is still irrelevant to the assignment given. This is because students are still lack in skill at identifying and expressing the proper ideas in essay writing based on the question. The thinking skills that are still low among the students make them unable to develop the essays accurately, cannot express the concept of the title clearly and cannot describe the content maturely. This is in line with Safiah et al. (2013) statements that mistakes made by students in essay writing at the STPM level are because students do not understand the real requirements of the title, inadequate knowledge, and non-critical and immature thinking.

Additionally, there are also students who cannot write a good and clear introduction to explain a topic rose in an essay question. This is coupled with the disadvantages of students who lack understanding of the concept of an issue in the essay writing so that the student's introduction is somewhat vague and less relevant to the requirements of the title which should be discussed in the paragraph of the essay. This shows that the student's level of thinking about an issue is still weak. Students' weakness in describing the issue of this topic is due to the attitude of most students who rely heavily on explanations and introductory notes provided by the teacher and this causes students to not using their own ideas in writing an introduction. These weaknesses are related to the teaching and learning process of the teachers who give less exposure to the students on creative, critical and analytical thinking culture as desired by the goal of the Ministry of Education. This is in line with Juriah (2010) findings that the teaching of Malay language in the classroom is often teacher centered and does not apply the teaching and learning strategies suggested by KBSM Malay Language Syllabus.

Other weaknesses made by the students in the essay writing are that the students are still weak in expressing the content concisely and relevantly to the scope of the question. The content presented by the students did not show their maturity as pre-university students. In expressing the essay content, students also tend to state the content on a repeating or overlapping basis. This demonstrates the inability of students to identify appropriate contents to develop their essays. In terms of the development, most students cannot describe the content clearly and not focusing on the stated content. The description made by the student is also less relevant to the questions that should be discussed. Most students' development is still less neat, less organized and less focused on the question. In this regard, this has led to the aspect of relevance which is a very important aspect in producing an essay is not clearly visible in student writing outcomes. This weakness indicates that students are still less skilled in using creative thinking and analytical thinking in their essay writing. This is also due to the lack of exposure of students to think creatively and analytically in the process of learning because most of the teaching and learning process of the essay at school is more focused on the notes provided by the teachers and the students simply copy the essay examples as directed by the teacher. This is quite compatible with 
Zamri's study (2014) that found that a subject would not succeed and excel if the teaching and learning still use traditional methods and did not care about thinking skills among students.

Other weaknesses in student essay writing are in terms of essay development. Most students are weak in processing and developing contents neatly and organized. The description presented by the students also deviates from the requirements of the topic and is less relevant to the topic that should be discussed. The cohesion and coherence aspects are also less emphasized by the students in the development of their essays. This is also related to the weakness of the students in using fluent and effective language in describing the contents of their writings. The thinking culture is less emphasized among the students in the process of teaching and learning is the main factor that makes students weak in developing an issue. Due to their weakness in developing the contents perfectly, the essays produced by them do not reach the number of words as set forth in the question instructions. This is in line with Zamri's (2014) statement which states that a more traditional approach to giving notes and memorizing can cause students fail to understand something meaningful in the lesson and thus causing them to not use the knowledge acquired to solve a problem.

This weakness also shows that creative, critical and analytical thinking skills are still less practiced by the students in producing their essays. This suggests that there are still many weak students in producing good quality and perfect essays in terms of discourse integrity. According to Rohana (2004), the cause of the drop in student achievement is due to lack of thinking skills in the teaching and learning process. This opinion was supported by a study by Rohaida and Zamri (2015) which found that the use of conventional methods in teaching and learning was less effective in improving the students' essay writing. The students are still plagued by traditional teaching methods that students only receive notes from teachers without being actively involved in learning. They are only required to copy a sample of the essays and never think of expressing the ideas or inventions themselves.

Accordingly, as the most recent teaching tool, the use of i-Think thinking map is seen as an effort to enhance the students' skills in writing non-formatted essays among Form 6 students. However, a study on the use of i-Think thinking map in the teaching and learning process, especially in its effectiveness in improving the essay writing skills is still lacking because the i-Think thinking map is a new thing introduced in this country. Therefore, the results of this study are expected to provide useful contributions to the teachers and make it one of the techniques to teach essay writing to the students.

\section{Research Purpose}

The general purpose of this study is to examine the effectiveness of the use of i-Think thinking map in the mastery of non-formatted essay writing skills among Form 6 students.

\section{Research Objective}

The objective of this study is to:

1. Identify differences in students' achievement in writing non-formatted essays by using i- 
Vol. 8, No. 4, 2019, E-ISSN: 2226-6348 C 2019 HRMARS

Think thinking maps and conventional methods in teaching and learning, and

2. Identify the effectiveness of using i-Think thinking map and the conventional method in writing non-formatted essays on the aspect of relevance and essay development.

\section{Research Question}

Specifically, this study aims to answer the following research questions:

1. Is there a significant difference in students' achievement in the non-formatted essays writing for the pre-test between the experimental group and the control group?

2. Is there a significant difference in students' achievement in the non-formatted essays writing for the post-test for the experimental group and the control group?

3. Is there a significant difference in students' achievement in non-formatted essay writing in terms of relevance between pre-test and post-test for the experimental group?

4. Is there a significant difference in students' achievement in non-formatted essay writing in terms of development between pre-test and post-test for the experimental group?

5. Is there a significant difference in students' achievement in non-formatted essay writing in terms of relevance in the post-test between the experimental group and the control group? and

6. Is there a significant difference in students' achievement in non-formatted essay writing in terms of development in the post-test between the experimental group and the control group?

\section{Methodology \\ Research Design}

This study uses a quantitative approach. The quantitative approach used is quasi-experimental design. According to Creswell (2012), this method is used to test an idea to identify whether there is an effect on the achievement (dependent variable). This approach is appropriate in this study to compare the effects of independent variables on the dependent variables. This quasiexperimental study is conducted to examine the effectiveness of a treatment program or the teaching and learning method selected by the researcher on the mastery of the students in writing the non-formatted essays.

\section{Quasi-Experimental Methods}

In this study, the researcher uses the quasi-experimental method which is aimed to test the effectiveness of using i-Think thinking map in the teaching and learning of non-formatted essay writing skills among Form 6 students. Students are divided into experimental groups and control groups. Experimental groups are taught using i-Think thinking maps, while control groups follow conventional teaching and learning. By using both teaching and learning approaches, researchers use quantitative data to see the effect of the two approaches used. According to Mahzan (2002), this study was able to control the extraneous variables, through the following ways: (1) Classes with the same background, (2) Same subject, (3) Same topic, (4) Same pre and post questions, (5) Same teaching duration, (6) Same week and (7) Same achievement. 
Vol. 8, No. 4, 2019, E-ISSN: 2226-6348 @ 2019 HRMARS

Pre-test and post-test design is used in this study to determine the effectiveness of teaching and learning using $\mathrm{i}$-Think thinking maps for experimental group and conventional teaching and learning for control group. Each group which are the experimental group and the control group will undergo two tests, namely pre-test and post-test. After pre-test, both groups were given treatment. The control group will follow conventional learning or traditional learning, while the experimental group will use i-Think thinking map in every teaching and learning of non-formatted essay. The design of the test is shown in Table 1.

Table 1: Test design (Creswell 2012)

\begin{tabular}{lcll}
\hline \multicolumn{1}{c}{$\begin{array}{c}\text { Experimental Group } \\
\text { Control Group }\end{array}$} & UI & $X$ & U2 \\
U1= Pre-test & Y & U2 \\
U2= Post-Test & & \\
$X=$ Treatment using i-Think thinking map & & \\
$Y=$ Treatment using conventional methods &
\end{tabular}

\section{Population and Samples}

According to Cohen et al. (2007), the quality of a study depends also on the suitability of the sampling strategy used by the researcher. Accordingly, the researcher should choose the appropriate sample to describe the study as a whole. Accurate and appropriate samples are very important to answer the questions raised in a study. Therefore, the population for this study is lower Form 6 who takes Malay language subject at the STPM level. The school studied was a secondary school in Mukah which has three classes for lower Form 6 with the total number of students is 70 .

However, out of the three classes, only two classes offer Malay language subject at the STPM level with a total of 40 students. This way, random distribution procedures are not used as the researchers used the existing classes in the school. The classes are Form 6BC (20 students) and Form 6BG (20 students). These two classes are divided into experimental group (6BC) and control group (6BG). Both groups were chosen because of their background in terms of demographic and achievement in Malaysian Certificate of Education (Sijil Pelajaran Malaysia, SPM). This is important to ensure that this study is not influenced by extraneous variables as well as to prevent research samples from affecting each other.

\section{Research Instruments}

A few research instruments have been used by researchers in this study, namely the experimental group lesson plan, lesson plan for the control group, pre-test and post-test.

\section{Lesson Plans}

In this study, lesson plans are designed into two groups. This plan is used after the researcher conducted pre-test for both groups. The lesson plan is used before the post-test. The lesson plans are as follows: 
Vol. 8, No. 4, 2019, E-ISSN: 2226-6348 @ 2019 HRMARS

\section{Lesson Plans Using I-Think Thinking Map}

This plan is used to teach an experimental group that is Form $6 B C$ consisting of 20 students. This teaching method was implemented 5 times before the post-test is conducted. The main thing emphasized in the lesson plan is the use of i-Think thinking map in the teaching of the nonformatted essay. In this lesson plan, students are encouraged to search for information related to an essay title using i-Think thinking map.

\section{Conventional Lesson Plans}

This plan is used to teach the control group that is Form 6BG consisting of 20 students. This conventional method is also used for 5 times before the post-test. This plan is more of a traditional teaching method that is a teacher-centered lesson plan.

\section{Set of Questions for the Pre and Post-Test}

The questionnaire was formulated by the researcher with the help of the Head of Malay Language Committee at the school studied. In the pre and the post-test, three essay questions are presented and students need to choose one of the questions. This form of question is in line with the actual STPM question. Pre-test was given to both groups prior to treatment. After the treatment is conducted, post-test is given to both groups. These tests are administered to see the level of students' achievement in the writing of non-formatted essay.

\section{Research Procedures}

After selecting the respondents, the students are divided into two groups based on the existing class which is the experimental group and the control group. Subsequently, the researchers administered the pre-test tor both groups for 1 hour 20 minutes to evaluate their initial achievement level in essay writing. After performing the pre-test, the two groups are taught to write non-formatted essays using two different methods in which the experimental group is being taught using i-Think thinking map, while the control group is taught using conventional methods. After going through five teaching and learning sessions, both groups were given posttest for 1 hour and 20 minutes. The post test was marked and then the researcher made a research report.

\section{Validity and reliability of the Instruments}

To determine the validity and reliability of the study, the researcher took certain steps to safeguard the validity and reliability of the study. In order to verify the lesson plan instruments, the researcher received the guidance from the Head of Language Field and the Head of the Malay Language Committee at the school studied. The Head of Language Field is the main trainer of $\mathrm{i}$ Think program at Mukah Division and a teacher with more than 10 years of teaching experience. He also monitored the implementation of i-Think program at schools in Mukah Division. For the pre-test and the post-test instruments, researchers also get guidance from both teachers. In addition, researchers also received guidance and supervision from research supervisors to ensure that the instrument of the study is valid and reliable. 
INTERNATIONAL JOURNAL OF ACADEMIC RESEARCH IN PROGRESSIVE EDUCATION AND DEVELOPMENT

Vol. 8, No. 4, 2019, E-ISSN: 2226-6348 @ 2019 HRMARS

\section{Data Analysis}

The process of analyzing the quantitative data is made using the Statistical Package for Social Sciences (SPSS) version 20. Pre-test and post-test are reviewed and inspected based on the scores achieved by the students from both groups in producing non-formatted essays (opinions and discussions). Data is collected and analyzed. Data analysis is made through inferential statistical analysis. Inferential statistical analysis is used to answer the research questions that have been made by the researcher. This analysis is also used to test the null hypothesis of the study. Inferential statistical analysis used in this study is t test. The independent t-test is used to test the null hypothesis involving two independent variables, while a dependent t-test is used to test the null hypothesis involving two dependent variables. The $t$ value for determining the difference level for the independent $t$ test and the dependent $t$ test is at a significant level of 0.05 .

\section{Research Findings}

Difference in the Non-Formatted Essay Writing Achievement Levels in the Pre-Test Overall Score of the Experimental Group and the Control Group

$\mathrm{H}_{0} 1$ : There is no significant difference in the total mean scores of the non-formatted essay writing achievement level in the pre-test between the experimental group and the control group.

Table 2 is the comparison of the two mean between the experimental group and the control group which showed that there is no significant difference with the value of $t(38)=-0.925, p>$ 0.05 . The results showed a significant value of 0.541 which is greater than the significant level 0.05. Therefore, the null hypothesis which stated that there is no significant difference in the level of achievement of a non-formatted essay writing in the overall mean score of the pre-test between the experimental group and the control group is accepted. The achievement of both groups for this pre-test is the same that means that the students are in the same intelligence group.

Table 2: Independent t-test on the level of achievement of the non-formatted essay writing of the overall pre-test mean score between the two groups

\begin{tabular}{ccccccc}
\hline GROUPS & Mean & $\begin{array}{c}\text { Mean } \\
\text { Difference }\end{array}$ & $\begin{array}{c}\text { Standard } \\
\text { Deviation }\end{array}$ & t & df & $\mathbf{p}$ \\
\hline Experimental & 22.85 & -1.4000 & 5.183 & -.925 & 38 & .541 \\
Control & 24.25 & & 4.351 & & & \\
\hline
\end{tabular}

Difference in the Achievement Levels of Non-Formatted Essay Writing in the Post-Test Overall Score of the Experimental Group and the Control Group

$\mathrm{H}_{0}$ 2: There is no significant difference in the total mean scores of the non-formatted essay writing achievement level in the post-test between the experimental group and the control group. 
Table 3 shows that the mean score of the Experimental Group is 36.40 (Standard deviation = 2.87) which is higher than the Control Group mean score that is 27.400 (Standard Deviation = 4.56). The mean difference for both groups is 9.000 . Based on Table 3 , independent t-test analysis showed that there is a significant difference in the level of achievement of non-formatted essay writing in the overall post-test mean scores between the experiment group and the control group, the value of $t(38)=7.470, p<0.05$. Therefore, the null hypothesis is rejected. This shows that the achievement in non-formatted essays writing for the experimental groups taught using $\mathrm{i}$-Think thinking map is higher than the control group taught using conventional methods.

Table 3: Independent t-test on the level of achievement of the non-formatted essay writing of the overall post-test mean score between the two groups

\begin{tabular}{ccccccc}
\hline GROUPS & Mean & $\begin{array}{c}\text { Mean } \\
\text { Difference }\end{array}$ & $\begin{array}{c}\text { Standard } \\
\text { Deviation }\end{array}$ & t & df & $\mathbf{p}$ \\
\hline Experimental & 36.400 & 9.000 & 2.872 & 7.470 & 38 & .000 \\
Control & 27.400 & & 4.558 & & & \\
\hline
\end{tabular}

\section{Difference of Achievement Levels for Relevance Aspects in the Non-Formatted Essay Writing between Pre-Test and Post-Test of the Experimental Group}

$\mathrm{H}_{03}$ : There is no significant difference in the relevance aspect achievement level in the nonformatted essay writing between the pre-test and the post-test mean score for the experimental group.

This study also identifies whether there is a difference in the achievement level for relevance aspect (introduction, content, and conclusion) in the non-formatted essay writing between the mean score of the pre-test and the post-test for the experimental group. Table 4 shows the mean of the pre-test is 11.750 with the standard deviation of 1.860 , while the mean for the post test is 16.550 with the standard deviation of 1.638 .

Table 4: Mean achievement for relevance aspect of essay writing in the pre-test and the posttest for the experimental group

\begin{tabular}{cccc}
\hline Test & N & Mean & Standard Deviation \\
\hline Pre-Test & 20 & 11.750 & 1.860 \\
Post-Test & 20 & 16.550 & 1.638 \\
\hline
\end{tabular}

The findings showed that the mean achievement in the post-test is higher than the pretest mean. The difference between these two tests is $-4,800$, as shown in table 5 . The $t$ test showed a significant mean difference between the pre-test and the post-test for the experimental group with the values of $t(19)=-10.020, p<0.05$. These significant differences prove that there has been an increase in the achievement of the relevance aspect in mastering 
Vol. 8, No. 4, 2019, E-ISSN: 2226-6348 ๔ 2019 HRMARS

the non-formatted essay after the students are taught using i-Think thinking map. Therefore, $\mathrm{H}_{0} 3$, that is, there is no significant difference in the level of achievement for relevance aspect in the non-formatted essay writing between the mean score of the pre-test and the post-test for the experimental group is rejected.

Table 5: The dependent t-test of the achievement level for the relevance aspect of the nonformatted essays in the mean scores of the pre-test and the post tests for the experimental group

\begin{tabular}{lccccccc}
\hline & \multicolumn{3}{c}{ Paired Differences } & & & \\
\cline { 2 - 5 } & Mean & $\begin{array}{c}\text { Standard } \\
\text { Deviation }\end{array}$ & $\begin{array}{c}\text { Standard } \\
\text { Error }\end{array}$ & t & df & p \\
\hline Pre-Post Test & -4.800 & 2.142 & .479 & -10.020 & 19 & .000 \\
\hline
\end{tabular}

Difference of Achievement Levels for the Development Aspect in the Non-formatted Essay Writing between the Pre-Test and the Post-Test for the Experimental Group

$\mathrm{H}_{0} 4$ : There is no significant difference in the development aspect achievement level in the nonformatted essay writing between the pre-test and the post-test mean score for the experimental group.

This study also examines whether there is a difference in mastering the development aspects of the essay for the experimental groups taught using i-Think thinking map. Achievement mean of mastery of development aspect in the pre-test and post-test of the experimental group sample is stated in Table 6. The finding showed that achievement mean of mastery of development aspect in the post-test is higher than the pre-test achievement mean. Achievement mean for pretest is 6.600 with standard deviation of 1.392, while the achievement mean for post-test is 10.300 with standard deviation of 1.081 .

Table 6: Achievement mean for development aspects of non-formatted essay writing in pre-test and post-test for the experimental groups

\begin{tabular}{cccc}
\hline Test & N & Mean & Standard Deviation \\
\hline Pre-Test & 20 & 6.600 & 1.392 \\
Post-Test & 20 & 10.300 & 1.081 \\
\hline
\end{tabular}

The data from paired sample t test which are the pre-test and the post-test for the experimental group is shown in Table 7. Based on Table 7, t-test shows a significant mean difference between pre-test and post-test for the experimental group with the value of $t(19)=-$ 9.983, $p<0.05$. This significant difference demonstrates that there is an increase in the mastery of the development aspects in the non-formatted essay writing after the treatment is given using i-Think thinking map. Therefore, $\mathrm{H}_{0} 4$ which stated that there is no significant difference in the level of achievement for the aspect of development in the non-formatted essay writing in the 
INTERNATIONAL JOURNAL OF ACADEMIC RESEARCH IN PROGRESSIVE EDUCATION AND DEVELOPMENT

Vol. 8, No. 4, 2019, E-ISSN: 2226-6348 @ 2019 HRMARS

pre-test and the post-test mean score for the experimental group is rejected.

Table 7: Dependent T-test on the achievement level for the development aspect of the nonformatted essay in the mean score of the pre-test and the post-test for the experimental group

\begin{tabular}{|c|c|c|c|c|c|c|}
\hline & \multicolumn{3}{|c|}{ Paired Differences } & \multirow[b]{2}{*}{$\mathbf{t}$} & \multirow[b]{2}{*}{ df } & \multirow[b]{2}{*}{$\mathbf{p}$} \\
\hline & Mean & $\begin{array}{l}\text { Standard } \\
\text { Deviation }\end{array}$ & $\begin{array}{l}\text { Standard } \\
\text { Error }\end{array}$ & & & \\
\hline Pre-Post Test & -3.700 & 1.658 & .371 & -9.983 & 19 & .000 \\
\hline
\end{tabular}

Difference in the Achievement Levels for the Relevance Aspects in the Non-Formatted Essay Writing in the Post-Test Mean Score of the Experimental Group and the Control Group

$\mathrm{H}_{05}$ : There is no significant difference in the level of achievement for the relevance aspect in the non-formatted essay writing in the post-test mean score between the experimental group and the control group.

In addition, this study also examines the achievement of mastery of the relevance aspect of the non-formatted essay writing in the post-test between the experimental group and the control group. Table 8 shows the achievements mean of the experimental group sample is 16.550 with the standard deviation of 1.638, and the control group's achievement mean is 13.200 with the standard deviation of 2.042. The t test for the achievement of the relevance aspect showed a significant difference between the experimental group sample and the control group sample with the value of $t(38)=5.724, p<0.001$. Therefore, $\mathrm{H}_{0} 5$ which stated that there is no significant difference in the level of achievement for the relevance aspect in the non-formatted essay writing in the mean score of the post-test for the experimental group and the control group is rejected.

Table 8: Independent t-test on the level of achievement for the relevance aspect of the nonformatted essay writing in the mean scores of the post-test between the two groups

\begin{tabular}{ccccccc}
\hline GROUPS & Mean & $\begin{array}{c}\text { Mean } \\
\text { Difference }\end{array}$ & $\begin{array}{c}\text { Standard } \\
\text { Deviation }\end{array}$ & $\mathbf{t}$ & df & $\mathbf{p}$ \\
\hline $\begin{array}{c}\text { Experimental } \\
\text { Control }\end{array}$ & 16.550 & 3.350 & 1.638 & 5.724 & 38 & .000 \\
\hline
\end{tabular}

Difference in the Achievement Levels for the Development Aspects in the Non-Formatted Essay Writing in the Post-Test Mean Score of the Experimental Group and the Control Group

$\mathrm{H}_{06}$ : There is no significant difference in the level of achievement for the development aspect in the non-formatted essay writing in the post-test mean score between the experimental group and the control group. 
Vol. 8, No. 4, 2019, E-ISSN: 2226-6348 @ 2019 HRMARS

Table 9 shows that the mean score for the experimental group is higher at 10.300 with the standard deviation of 1.081 compared with the control group of 7.950 with the standard deviation of 1.146. The t test also showed a significant difference with the value of $t(38)=6.671$, $p<0.001$. Therefore, $\mathrm{H}_{0} 6$ which stated that there is no significant difference in the level of achievement in the aspect of development in the non-formatted essay writing in the mean score of the post-test between the experimental group and the control group is rejected.

Table 9: Independent t-test on the level of achievement for the development aspect of the nonformatted essay writing in the mean scores of the post-test between the two groups

\begin{tabular}{ccccccc}
\hline GROUPS & Mean & $\begin{array}{c}\text { Mean } \\
\text { Difference }\end{array}$ & $\begin{array}{c}\text { Standard } \\
\text { Deviation }\end{array}$ & $\mathbf{t}$ & df & $\mathbf{p}$ \\
\hline Experimental & 10.300 & 2.350 & 1.081 & 6.671 & 38 & .000 \\
Control & 7.950 & & 1.146 & & & \\
\hline
\end{tabular}

\section{Discussion}

This study clearly shows that the use of i-Think thinking map has helped many students to produce a better essay than conventional teaching and learning. The findings show that the mean score of the experiment group is higher than the mean score of the control group. This shows that students who have been taught using i-Think thinking map is successful in producing a better non-formatted essay compared to group of students taught using conventional method. This finding is in line with the research conducted by Rohaida and Zamri who found that the use of $\mathrm{i}$ Think thinking map has shown a positive impact in improving the students' skill in writing essays among year 6 students. Similarly, the study conducted by Izzudin and Zamri (2016) are in line with this study which found that the use of i-Think thinking map has increased students' achievement in Malay language skills. This study is also in line with Laura (2011) study that found that student's achievement improved through a method that uses thinking map in teaching and learning. Similarly, the study conducted by Jumailah and Zamri (2013) found that the use of iThink thinking map in Malay Language learning can improve students' achievement in Malay language. This is said to be because the use of the latest and interesting teaching materials is also important in enhancing student's creativity in producing writing.

The findings also showed that there are significant differences in the mean score of the students in pre-test and post-test for the experimental group in terms of relevance. The findings show that after the treatment using i-Think thinking map, students' achievement in writing essay from relevance aspect increased. Student's scores in terms of introduction writing, content identification and conclusion writing have shown a high improvement. It is also true if compared to the group taught conventionally. Based on this study, there is a significant difference in the mean score of the group being taught using i-Think thinking map and the group being taught conventionally in terms of relevance. This finding suggests that the use of $i$-Think thinking maps has helped students writing better introduction, identifying content more accurately and writing essays conclusion concisely, clearly and perfectly.

The findings are consistent with the study conducted by Hyerle (2000) that the use of thinking 
map can improve cognitive thinking skills among students. The improvement in thinking skills among students has helped them to express the more relevant content of the essay according to the needs of the questions. This study is also in line with the study conducted by Farihah and Zamri (2013) that the use of i-Think thinking map has a positive impact on the achievement of students in the subjects being taught. This clearly shows that the use of i-Think thinking maps actually helps students to increase their creative thinking skills and thus help students better and accurately identify the content of the essay. The study conducted by Ismail (2009), Ikhsan and Rohizani (2010), and Nordin (2013) also found that the use of graphic and pictorial materials can stimulate thinking, facilitating understanding and strengthening student memory. This clearly shows that the use of $\mathrm{i}$-Think thinking maps has helped students better identify the contents of the essays and make their descriptions concisely and pithily.

This study has also identified the difference in mean scores of pre-test and post-test in terms of development aspect for the experimental groups. The results showed that there is a significant difference in the mean score of the pre-test and the post-test from the development aspect of the experimental group. This shows that the use of thinking map affects the students in developing essays. The essay produced by the students after receiving the treatment using iThink thinking map has been well-crafted and solid. Cohesion and coherence aspects exist in the development of their essays. Significant differences also exist in terms of development between the experimental group and the control group. Experimental group obtained high mean scores from development aspects compared to control group. This shows that students who are taught using i-Think thinking map have worked on a better essay than students who has been taught using conventional method. This study is in line with the study conducted by Yahya and Azmey (2012) which found that the use of mind map has improved the students' achievement in developing essays compared with the group receiving conventional teaching and learning. This is in line with this study that the experimental group taught using i-Think thinking map has successfully develops the essay better than the control group. This proves that students' thinking patterns change when they are taught using appropriate and effective methods.

From this study it can be concluded that the use of i-Think thinking map among students actually allows students to be more focused and more interested in the subjects learned. This is proved by the scores obtained by the experimental group which is better than the control group in the post test. This study is in line with the study conducted by Puteh (2012) that the application of creative and critical thinking elements should be applied to each student. This is important in order to produce more creative and critical students as well as to attract students' focus on the subject. Thinking culture among students has been implemented through the use of i-Think thinking map because students can develop their essays concisely and perfectly. Accordingly, the use of i-Think thinking map is one of the best teaching methods to attract students and help to produce more creative and critical thinking students. This is also in line with the study of Rasid and Hasmah (2013) which states that the use of various teaching aids should be used by the teachers in an effort to attract and enhance students' creativity. Studies conducted by Fullan (2007) are also in line with this study as the willingness of teachers who act as an implementer is an important factor in ensuring success in changing the practice and culture during the teaching 
Vol. 8, No. 4, 2019, E-ISSN: $2226-6348$ @ 2019 HRMARS

and learning process. In this regard, this study which relates to the use of i-Think thinking map is an appropriate method to be used by the teachers in improving the thinking culture among students.

\section{Conclusion}

In conclusion, this study as a whole has shown that the use of i-Think thinking map in teaching and learning has helped to improve the students' achievement in writing non-formatted essays among form 6 students. In implication, this study found that the more recent teaching and learning method is ideally suited to produce creative and critical thinking students. By practicing high-thinking culture among the students, it will essentially help teachers to attract students to a subject. This means that more conventional teaching methods, which are more focused on the teachers, are irrelevant nowadays.

In this regard, more innovative teaching and learning methods such as the use of i-Think thinking map should be applied by the modern-day teachers in order to produce students with first-class minds. However, a more comprehensive study on the use of i-Think thinking map in improving the thinking culture among students should be implemented.

\section{References}

Bakar, A. N. (2013). Curriculum Towards Creating Critical, Creative and Innovative Thinking Skills. Journal of the Asia-Pacific Curriculum and Teaching, 1 (1), 10-17.

Cohen, L., Manion, L., \& Morrison, K. (2007). Research Methods in Education. 6th Edition. New

Creswel, J. W. (2012). Educational Research: Planning, Conducting and Evaluating Quantitative and Qualitative Research. University of Nebraska: Pearson Press.

Curriculum Development Division, Ministry of Education Malaysia.

Farihah, N. N. N. H., \& Zamri, M. (2013). The effectiveness of the Mapping Method (iThink) on the Achievement, Attitude, Willingness and Acceptance of form four pupils. in Zamri, M. et al. (editor.) Proceedings of the Second Seminar on Malay Language \& Malay Literature on the Faculty of Malay Secondary Education 2013, 423-440. Bangi: Publisher of Faculty of Education, National University of Malaysia.

Fullan, M. (2007). The New Meaning of Educational Change. 4th Edition. New York: Teacher's College Press.

Hyerle, D. (2000). Thinking maps: Visual Tools for Activating Habits of Mind. In A.L. Inquiry based Science Education for Fifth-Grade Students. Boston: Franklin Pierce Press.

Ikhsan, O., \& Rohizani, Y. (2010). The Application of Multiple Intelligence Theories in the Implementation of the Curriculum. Asia Pacific Journal of Educators and Education, 25, 2132.

Ismail, Z. (2009). The Importance of Mind Map. Accessed from http://www.tutor.com.my

Jumailah, M., \& Zamri, M. (2013). Use of thought Map (i-Think) in Secondary School Malay Language Learning. In Zamri, M. et al. (editor). Proceedings of the Regional Seminar on Postgraduate Education on Malay Language \& Malay Secondary Literature 2013, 397- 410. Bangi: Publisher of the Faculty of Education, Universiti Kebangsaan Malaysia.

Juriah, L. (2010). Scenario and Teaching Challenge, Learning the Current Malay Language. In Juriah, L. (editor.). Methods of Teaching and Learning Malay Language, 17-32. Bangi: 
INTERNATIONAL JOURNAL OF ACADEMIC RESEARCH IN PROGRESSIVE EDUCATION AND DEVELOPMENT

Vol. 8, No. 4, 2019, E-ISSN: 2226-6348 @ 2019 HRMARS

Publisher Universiti Kebangsaan Malaysia.

Laura, A. W. (2011). The effect of Thinking Maps on Students' Higher Order Thinking Skills. California: California State University.

Mahzan, A. A. (2002). Socio-economic Research Methods. Kuala Lumpur: Dewan Bahasa dan Pustaka.

Malaysia Education Ministry. (2015). The i-Think Draft Book. Putrajaya: The Publisher of the

Malaysian Examinations Council. (2011). Malay Language: Syllabuses and Example Sample Papers. Selangor: Publisher Tihani Cetak Sdn. Bhd.

McLeod, S. (2009). Simply psychology. Accessed from http://www.simplypsychology. org/piaget.html. [5 Mac 2016]

Nor, S. P. (2012). The Concern of Malay Language Teachers in Performing Critical

Rasid, A. J., \& Hasmah, I., (2013). The Implementation Of Learning In Teaching Malay Language . Journal Malay Language Education, 3 (2), 49-63.

Rohaida, Y., \& Zamri, M. (2015). Effectiveness of the Thinking Map (i-Think) Improving the Achievement of Malay Language Writing for Year 6. Jurnal Malay Language Education, 5 (2), 31-37

Rohana, N. M. (2004). Writing Essays and Language Skills. Kuala Lumpur: Dewan Bahasa \& Pustaka.

Safiah, N. K., Norliza, J., \& Raminah, S. (2013). Text STPM Malay Language Chapter 1. Selangor: Publisher Oxford Fajar Sdn. Bhd.

Thinking Skills and Creative Thinking. Journal of Malay Language Education, 2 (2), 19- 31.

Yahya, O., \& Azmey, O. (2012). The Effectiveness of Using Mind Maps in Teaching and Learning Arguments in an Arabic high school in Brunei Darussalam. Journal Malay Language Education, 2 (2), 32-45.

Yahya, O., Roselan, B., \& Naffi, M. (2009). Empowering Malay Language Education from Theory to Practice. Kuala Lumpur: Publisher of Utusan Publications \& Distibutor Sdn Bhd.

York: Routledge Taylor \& Francis Group Press.

Zamri, M. (2014). Learninag Innovation in Malay Language Education. Third Print. Tanjung Malim: Publisher University of Sultan Idris. 